\title{
A importância da potabilidade da água no saneamento básico para a promoção da saúde pública no Brasil
}

The importance of water potability in basic sanitation for public health promotion in Brazil

\author{
Taiara Damke, Fernando Pasini*
}

Como citar esse artigo. Damke,

T; Pasini, F. A importância da potabilidade da água no saneamento básico para a promoção da saúde pública no Brasil. Revista Teccen. 2020 Jan./Jun.; $13 \quad$ (1): 08-15.

\author{
Resumo \\ O tratamento e abastecimento da água são imprescindíveis à manutenção da qualidade de vida da população, visto que \\ a água além de essencial ao organismo humano é o principal meio de proliferação de endemias. Assim, este trabalho \\ visa descrever e analisar a importância da água potável, para a promoção da saúde pública, contextualizar as legislações \\ aplicadas e a situação do saneamento básico no Brasil. Este estudo tem caráter bibliográfico e descritivo, para sua \\ elaboração foram utilizados documentos e informações sobre o saneamento básico e sua relação com a saúde pública. \\ Os resultados indicaram que são necessários esforços tanto de abordagens tecnológicas apropriadas para as unidades \\ e sistemas de abastecimento, como políticas públicas, onde se necessita auxílio do poder público para a formulação, \\ avaliação, organização das legislações e demais programas voltados ao tema. De forma que por meio do saneamento \\ básico garanta-se qualidade de vida para a população. \\ Palavras-Chave: Qualidade da Água; Gestão de Recursos Hídricos; Qualidade de Vida.
}

\begin{abstract}
The treatment and supply of water are essential for maintaining the quality of life of the population, since water beyond what is essential for the human organism is the main means of proliferation of endemic diseases. Thus, this work aims to describe and analyze the importance of drinking water, for the promotion of public health, to contextualize it as applied legislation and a situation of basic sanitation in Brazil. This study has a bibliographic and descriptive character, for its elaboration, documents and information about basic sanitation and its relationship with public health are used. The results indicate that the appropriate technological approaches are adopted for the supply units and systems, as well as public policies, where the benefits of the public power for the tests, evaluations, organization of legislation and other programs focused on the theme. So that the means of basic sanitation guarantees the quality of life of the population.
\end{abstract}

Keywords: Water quality; Water Resources Management; Quality of life.

\section{Introdução}

O saneamento básico é essencial para a qualidade de vida da população, dentre os seus pilares dá-se relevância para o tratamento e abastecimento de água, visto que é imprescindível à vida e também o principal meio de veiculação de doenças, portanto, constituise fator de grande preocupação aos órgãos gestores. A água no decorrer da história da humanidade, teve suas necessidades de uso modificadas e a tecnologia proporcionou o estabelecimento de padrão de qualidade mais exigente e determinou os volumes necessários às diversas atividades.

Os principais usos da água para abastecimento humano são: a preparação alimentícia, limpeza doméstica, higiene pessoal além da hidratação corporal. $\mathrm{Na}$ água podem ser encontrados diversos compostos como sais dissolvidos, partículas em suspensão e microrganismos que, dependendo da sua concentração, podem causar alterações à saúde humana. No entanto, quando isenta de agentes patógenos e dentro do padrão de potabilidade, contribui para a manutenção de um organismo sadio (Tsutiya, 2006).

Em comunicado oficial realizadopela Organização Mundial da Saúde (OMS), em 2014, foi indicado que a cada R\$ 1,00 investido em saneamento, resulta na economia de R \$ 4,00 (que seriam investidos em saúde corretiva) (WORLD HEALTH ORGANIZATION, 2014). Assim sendo, observa-se que o investimento em saneamento vai além da melhora na qualidade de vida da população, é também forma eficaz de prevenção

Afiliação dos autores:

Discentes de pós-graduação, Universidade Anhanguera - LFG, Santa Rosa - RS, Brasil

* Email para correspondência: eng.fpasini@gmail.com 
epidemiológica, a qual, a médio/longo prazo reverte-se em economia aos cofres públicos.

Desta forma, entende-se que políticas públicas de investimento em longo prazo, são necessárias para melhoria da saúde pública. No entanto, de acordo com Peixoto (2013), a expansão vagarosa do saneamento básico, incluído o atendimento precário, a inadequada gestão e a falta de sustentabilidade técnica e econômica da maior parte dos serviços, podem ser atribuídos, em grande parte, à falta de diretrizes e normativas legais de âmbito nacional. Logo, este trabalho visa descrever e analisar a importância da água potável no saneamento básico para a promoção da saúde pública no Brasil.

\section{Materiais e Métodos}

Esta pesquisa tem caráter bibliográfico e descritivo, para sua elaboração utilizou-se de ferramentas digitais de busca, a fim de encontrar materiais que abordassem o foco principal deste estudo: o saneamento básico e como a saúde pública pode ser impactada por este. Os materiais foram encontrados em fontes diversas relacionadas ao tema como: legislações, literatura científica especializada e sistemas de informações governamentais, como o SNIS (Sistema Nacional de Informações sobre Saneamento).

\section{Resultados e Discussão}

A apresentação dos resultados e discussão ocorrerá contextualizando as legislações aplicadas e a situação do saneamento básico no Brasil, os problemas relacionados à saúde pública que possam ocorrer devido à falta de água potável, e relatos da importância da qualidade da água no saneamento básico.

\section{Saúde Pública}

Para Winslow (1920), apud Gazola (2008), saúde pública é definida como:

\begin{abstract}
A arte e a ciência de prevenir a doença, prolongar a vida, promover a saúde e a eficiência física e mental mediante o esforçoorganizado dacomunidade.Abrangendoo saneamento do meio, o controle das infecções, a educação dos indivíduos nos princípios de higiene pessoal, a organização de serviços médicos e de enfermagem para o diagnóstico precoce e pronto tratamento das doenças e o desenvolvimento de uma estrutura social que assegure a cada indivíduo na sociedade um padrão de vida adequado à manutenção da saúde.
\end{abstract}

O acesso à saúde está relacionado às condições de vida: alimentação; moradia; riqueza; e, educação. Tal acessibilidade aos serviços vai além do espaço geográfico, abrangendo também o aspecto econômico referente a todos os gastos do utilizador do serviço, a cultura envolvendo normas e técnicas apropriadas aos costumes da população e a funcionalidade pela oferta de serviços adequados de acordo com a necessidade apresentada do usuário (Unglert, 1995).

Assim sendo, a integração entre os planos e programas de saúde e de saneamento no Brasil é aceita e vista como necessária, no entanto, não efetivada. Assim sendo, os programas de saúde limitam-se a uma ação de caráter mais corretivo, não articulando-se com estratégias universais, onde a prevenção é priorizada (Sperling, 2003).

\section{Saneamento Básico}

Saneamento pode ser definido como o controle de todos os fatores do meio físico do ser humano, que causam ou podem causar efeitos nocivos sobre o bem estar físico, mental e social (OMS, 2014). Doutro modo, pode-se dizer que saneamento representa o conjunto de ações socioeconômicas que tem por finalidade atingir sanidade ambiental.

Conforme Heller (1998), o Brasil tem considerado como integrantes do saneamento as ações de:

- Abastecimento de água, que é o fornecimento de água em quantidade suficiente e com qualidade dentro dos padrões de potabilidade para a população;

- Esgotamento sanitário, que compreende a coleta dos esgotos e sua disposição adequada com a capacidade do meio ambiente em assimilá-los;

- Limpeza pública, que inclui todas as fases de manejo dos resíduos sólidos domésticos, desde a coleta até sua disposição final, sendo este compatível com as condições do meio ambiente;

- Drenagem pluvial, caracterizado pela condução das águas pluviais, de forma a minimizar seus efeitos negativos, como o aumento da insalubridade desta área, sobre as populações e as propriedades e;

- Controle de vetores de doenças transmissíveis.

\section{Relação entre saúde e saneamento}

Alguns modelos foram apresentados para explicar a relação entre as ações de saneamento e a saúde, estes têm privilegiado as ações sanitária do abastecimento de água e do esgotamento sanitário sem detrimento as demais, como coleta e tratamento de resíduos e drenagem urbana (Heller, 1998). Um exemplo é o modelo apresentado por Cvjetanovic (1986) (Figura 1) o qual relaciona os efeitos diretos e indiretos que algumas ações de saneamento podem resultar em relação à saúde humana.

A falta de saúde nomeia-se doença, causa frequente de morbidade e mortalidade. Ainda que haja métodos eficientes para a sua prevenção e controle, estes não são adequadamente empregados pela sociedade e 


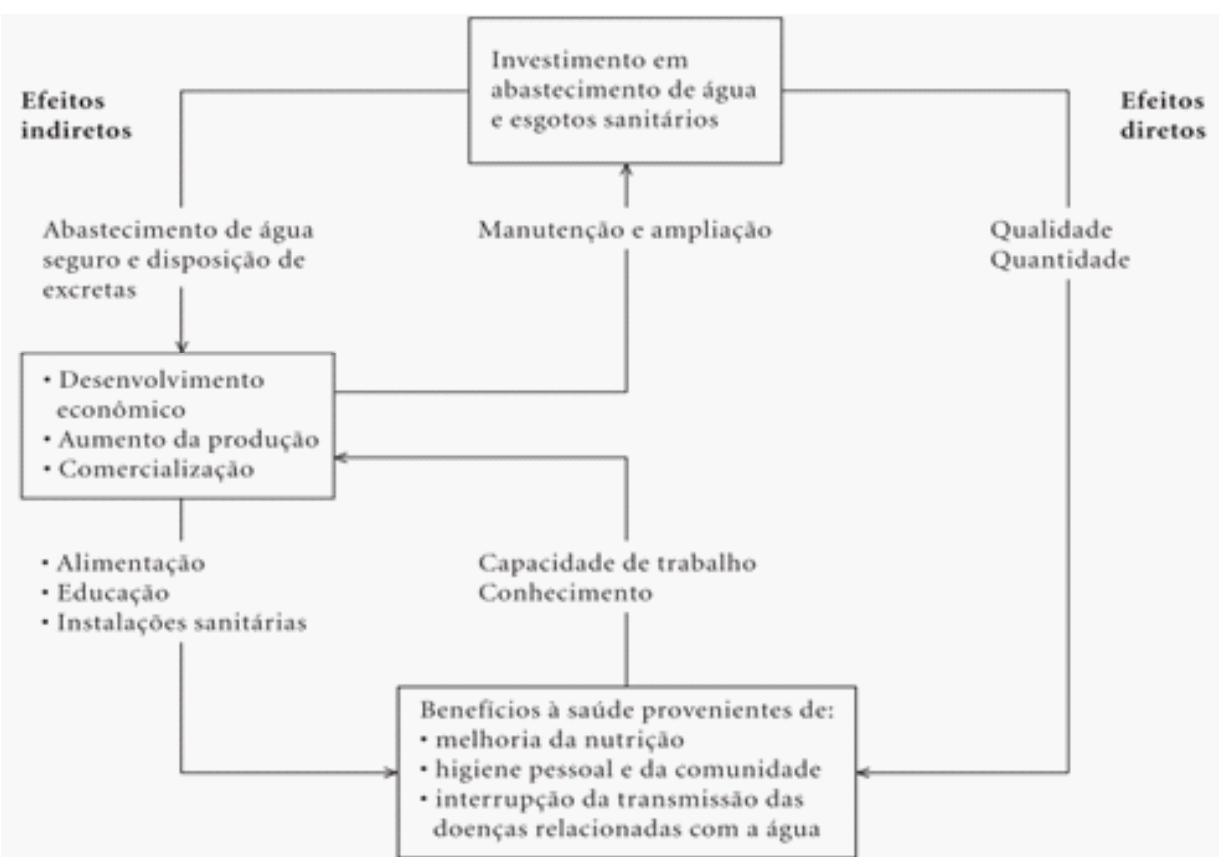

Figura 1. Efeitos diretos e indiretos do abastecimento de água e do esgotamento sanitário sobre a saúde: esquema conceitual.

Fonte: Heller, 1998

acabam sendo destinados somente ao controle, assim sua eficiência é pouca ou nenhuma (Natal, 2000, apud Giafferis, 2001).

\section{Legislação Aplicada}

A Constituição Federal de 1988 apresenta, em seu art. 225, que "todos têm direito ao meio ambiente ecologicamente equilibrado, bem de uso comum do povo e essencial à sadia qualidade de vida, impondo-se ao poder público e à coletividade o dever de defendêlo e preservá-lo para as atuais e futuras gerações”. E no artigo 196 da Constituição Federal, que trata sobre saúde, é apresentado que "A saúde é direito de todos e dever do Estado, garantido mediante políticas sociais e econômicas que visem à redução do risco de doença e de outros agravos e ao acesso universal e igualitário às ações e serviços para sua promoção, proteção e recuperação".

Partindo de tais conceitos atribuídos pela Constituição Federal de 1988, pode-se notar a relação entre meio ambiente, saúde e saneamento, pois não há qualidade de vida e redução dos riscos de doença sem saneamento básico. Esse fato fica evidente quando na Constituição, no seu Art. $200^{\circ}$, Inciso IV, atribui-se às competências do SUS (Sistema Único de Saúde) "executar as ações de vigilância sanitária e epidemiológica, bem como as de saúde do trabalhador, e participar da formulação da política e da execução das ações de saneamento básico".

Neste sentido, uma das leis que institui um marco importante envolvendo saneamento básico foi a Lei
Federal $n^{\circ} 11.445$ de 5 de janeiro de 2007 que instaurou as diretrizes nacionais para o saneamento básico e para a política federal de saneamento básico. Essa também estabelece o saneamento básico como o "conjunto de serviços, infraestruturas e instalações operacionais de abastecimento de água potável, esgotamento sanitário, limpeza urbana e manejo de resíduos sólidos, drenagem e manejo das águas pluviais, limpeza e fiscalização preventiva das respectivas redes urbanas".

Por meio da Lei de Saneamento Básico (Lei 11.445/07), também foi determinado que todas as prefeituras têm obrigação de elaborar seu Plano Municipal de Saneamento Básico (PMSB). Pois sem este documento, a partir de 2014, a Prefeitura não poderia receber recursos federais para projetos de saneamento básico. Esse também foi um grande avanço onde os municípios se obrigaram em se estruturar, no entanto, ainda não é a solução, visto que planos não estancam o problema em um mesmo momento (Peixoto, 2013).

A Lei $n^{\circ}$ 9.433/1997 (Política Nacional de Recursos Hídricos - PNRH) também é de grande importância e ampla abrangência. Ela cria o Sistema Nacional de Gerenciamento de Recursos Hídricos (SINGREH), e institui em seus fundamentos que a gestão dos recursos hídricos deve ser descentralizada e contar com a participação do Poder Público, dos usuários e das comunidades, assim atribuindo a todos o dever de mantê-la em condições adequadas.

De acordo com Peixoto (2013), também são importantes outras diretrizes da PNRH e, com relação à temática do saneamento básico, pode ser destacado que a PNRH trata da cobrança pelo uso dos recursos hídricos, 
para a captação de água para abastecimento público, para o lançamento de efluentes no meio ambiente (como em rios), a outorga do direito de uso de recursos hídricos, de efluentes dos sistemas de tratamento de esgotos sanitários e de resíduos sólidos, forma a organizar e promover a compatibilidade da demanda com o recurso disponível.

Também são de grande importância e contribuem nas legislações voltadas para essa área as seguintes normas:

- Lei $n^{\circ} 10.257 / 2001$ (Estatuto das Cidades) que estabelece normas de ordem pública e interesse social que regulam o uso da propriedade urbana em prol do bem coletivo, da segurança e do bem-estar dos cidadãos, bem como do equilíbrio ambiental.

- Decreton ${ }^{\circ} 5.440 / 2005$, que estabelece definições e procedimentos sobre o controle de qualidade da água de sistemas de abastecimento e criou métodos e instrumentos para divulgação de informações ao consumidor sobre a qualidade da água para consumo humano.

- Portaria no 2.914/2011, do Ministério da Saúde, que dispõe sobre procedimentos de controle e vigilância da qualidade da água para consumo humano e seu padrão de potabilidade. Esta se torna essencial para a saúde do ser humano visto que nela se encontram os padrões necessários para o consumo.

Além das leis já citadas, as resoluções do CONAMA (Conselho Nacional do Meio Ambiente) também são de suma importância neste contexto. Podem-se citar as resoluções no 357/2005 que dispõem sobre a classificação dos corpos de água e as diretrizes para o seu enquadramento e a $n^{\circ} 397 / 2008$ que apresenta as condições e os padrões de lançamento de efluentes no meio ambiente, assim também auxiliando para manter a qualidade dos corpos hídricos.

A resolução CONAMA n ${ }^{\circ}$ 430/2011, que complementa e altera a resolução $n^{\circ} 357$, dispõe sobre as condições e padrões de lançamento de efluentes. Tal resolução também é essencial para manter os padrões dos recursos hídricos, visto que tal visa garantir que os lançamentos de esgoto atendam valores que o meio ambiente possa estabilizar.

Também é relevante citar a Resolução CONAMA $n^{\circ} 377 / 2006$, que dispõe sobre o licenciamento ambiental simplificado de sistemas de esgotamento

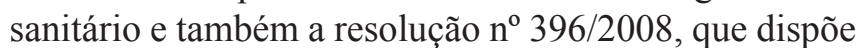
sobre a classificação e as diretrizes ambientais para 0 enquadramento das águas subterrâneas.

Peixoto (2013) ressalta que teve-se um grande avanço nas legislações conferidas ao meio ambiente através do poder público, no entanto, a efetuação das políticas de saneamento básico, na realidade, ainda se encontra deficitária, com pouca eficiência e eficácia.

\section{Saneamento Básico no Brasil}

Pelo impacto na qualidade de vida, na saúde, na educação, no trabalho e no ambiente, o saneamento básico envolve a atuação de múltiplos setores em uma vasta rede. No entanto, o Brasil é marcado por desigualdades econômicas o que reflete no acesso ao saneamento, e os principais déficits referem-se à coleta $\mathrm{e}$ tratamento de esgoto (Leoneti, Prado \& Oliveira, 2011). No entanto a desigualdade social reflete-se também na distribuição de água de boa qualidade (Vieites, 2008).

Conforme apresentado pelo SNIS (2016), o Saneamento básico ainda é tratado como de menor importância no Brasil, apesar de ser um direito assegurado pela Constituição e definido pela Lei ${ }^{\circ}$ $11.445 / 2007$, que estabelece diretrizes nacionais para o saneamento básico. No panorama também retratado pelo SNIS (2016) é colocado que se reconhece que o país está longe de possuir uma saúde pública adequada o que causa a deterioração dos recursos ambientais, principalmente os hídricos, o que se torna o principal fator da falta de potabilidade da água.

Os dados apresentados pelo SNIS em 2016 (Quadro 1), a nível nacional, mostram que somente $51,9 \%$ da população têm seu esgoto coletado e 83,3\% da população possui sistema de abastecimento de água. Quando considerando somente os dados por região, a região norte é a que mais sofre pela falta desses serviços, apenas $55,4 \%$ da população possui abastecimento de água.

Os valores melhoramumpouco quando comparado o total com somente as áreas urbanas, onde o índice de atendimento com rede de água de $93 \%$ e de coleta de esgoto de $59,7 \%$. No entanto, ainda são valores que se considerado o dado em números da população que não é atendida, extremamente significativas, principalmente se tratando de coleta de esgoto. Desta forma, estes números representam que ainda estamos longe de chegar a um padrão necessário para o saneamento no Brasil.

O Quadro 1 também apresenta que somente 44,9 $\%$ dos esgotos gerados tiveram tratamento no Brasil e já dos esgotos coletados foram $74,9 \%$. O índice de tratamento de esgoto é de grande relevância para a qualidade da água, observando que a maior parte desse efluente é lançada em um recurso hídrico, o que afeta e qualidade da água e de quem depende da mesma (SINS, 2016).

Assim sendo, para expressar melhor a situação brasileira, a Figura 2 apresenta o índice de atendimento urbano de água através dos dados obtidos pelo SNIS (2016), onde pode-se observar que a região norte do país, mais especificamente os estados do Amapá, Pará e Rondônia são os que mais sofrem com a falta de distribuição de água potável.

Segundo informações dos prestadores de serviços 
Quadro 1. Níveis de atendimento com água e esgotos dos municípios cujos prestadores de serviços são participantes do SNIS em 2016, segundo região geográfica e Brasil.

\begin{tabular}{|l|c|c|c|c|c|c|}
\hline \multirow{3}{*}{ Região } & \multicolumn{3}{|c|}{ Índice de atendimento com rede (\%) } & \multicolumn{2}{c|}{$\begin{array}{c}\text { Indice de tratamento } \\
\text { dos esgotos (\%) }\end{array}$} \\
\cline { 2 - 7 } & \multicolumn{2}{|c|}{ Água } & \multicolumn{2}{c|}{ Coleta de Esgoto } & $\begin{array}{c}\text { Esgoto } \\
\text { Gerado }\end{array}$ & $\begin{array}{c}\text { Esgoto } \\
\text { Coletado }\end{array}$ \\
\cline { 2 - 7 } & Total & Urbano & Total & Urbano & Total & Urbano \\
\cline { 2 - 7 } & 55,4 & 67,7 & 10,5 & 13,4 & 18,3 & 81,0 \\
\hline Norte & 73,6 & 89,3 & 26,8 & 34,7 & 36,2 & 79,7 \\
\hline Nordeste & 91,2 & 96,1 & 78,6 & 83,2 & 48,8 & 69,0 \\
\hline Sudeste & 89,4 & 98,4 & 42,5 & 49,0 & 43,9 & 92,9 \\
\hline Sul & 89,7 & 97,7 & 51,5 & 56,7 & 52,6 & 92,1 \\
\hline Centro-oeste & 83,3 & 93,0 & 51,9 & 59,7 & 44,9 & 74,9 \\
\hline Brasil & \multicolumn{7}{|c|}{} & & & \\
\hline
\end{tabular}

Fonte: SINS (2016).

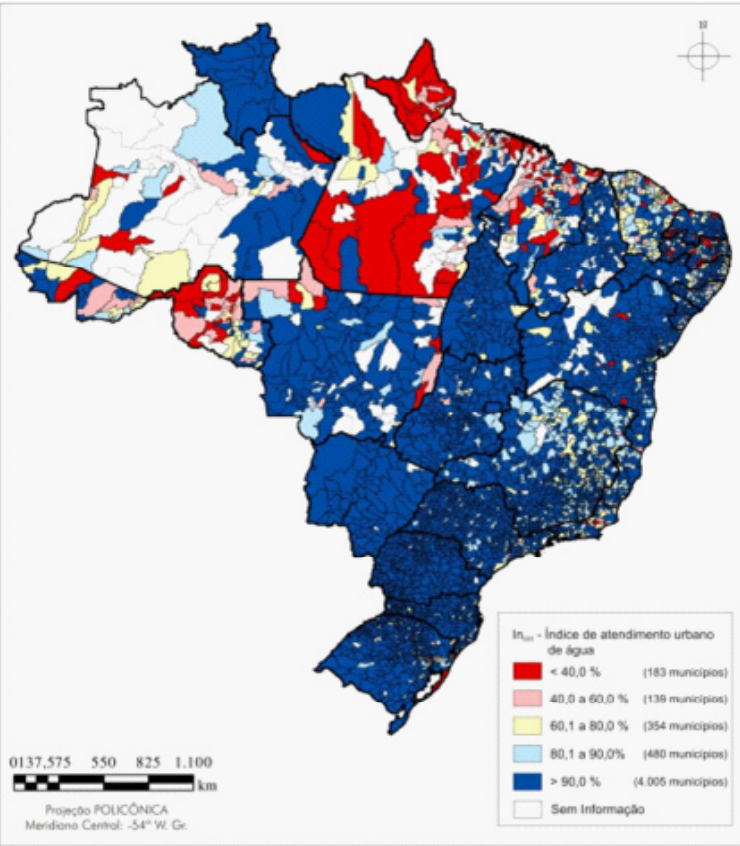

Figura 2. Representação espacial do índice de atendimento urbano por rede de água distribuído por faixas percentuais, segundo município.

Fonte:SINS (2016)

apresentados pelo SNIS (2016), são 2.428 municípios registrados que possuem índice de atendimento urbano por rede de água igual a $100 \%(47 \%$ do total de municípios da amostra). Analisando por número de habitantes, esses municípios correspondem a $42,3 \%$ da população urbana residente destes dados. Assim sendo, esse é o percentual de população urbana do país que possui acesso aos serviços de água que está universalizado.

Na Figura 3 pode-se observar a distribuição pelo Brasil do índice de atendimento urbano por rede coletora de esgoto apresentados pelo SNIS (2016), onde 1526 apresentaram índice superior a $70 \%$ de coleta e tais municípios se encontrando em sua maioria no sudoeste

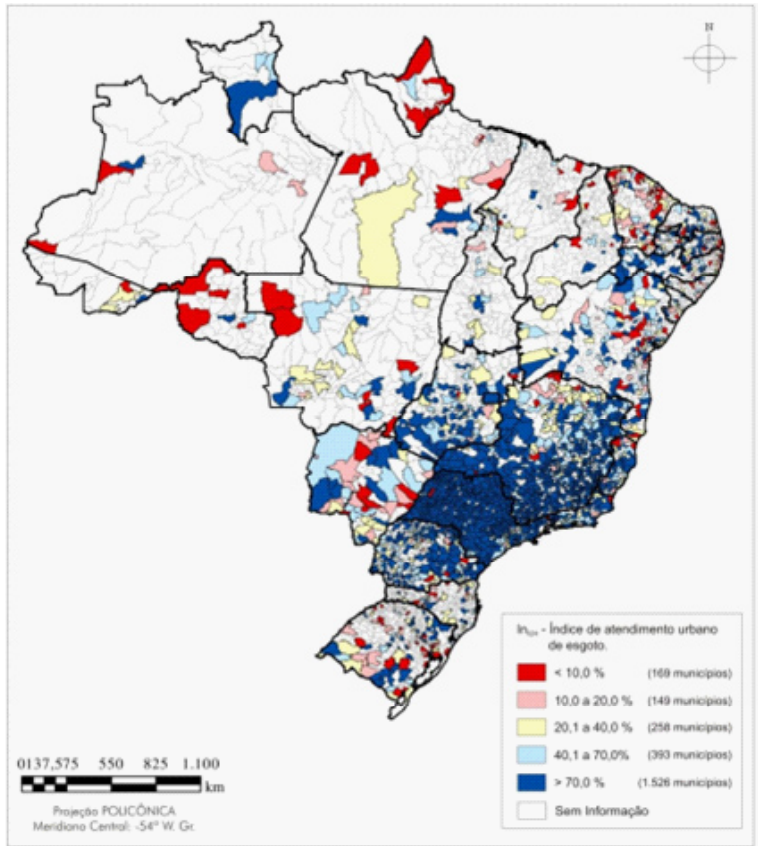

Figura 3. Representação espacial do índice de atendimento urbano por rede coletora de esgotos distribuído por faixas percentuais, segundo município.

Fonte:SINS (2016).

do país. O índice de coleta de esgoto não está nem próximo dos valores alcançados pelo abastecimento de água, desta forma, o mesmo espera-se que venha a melhorar nos próximos anos.

\section{A importância do saneamento básico}

Embora a saúde e a higiene tenham se tornado causas de preocupações de políticas públicas na América Latina desde o século XIX, apenas nos últimos anos, mais especificamente, desde os anos 90, o acesso aos sistemas de abastecimento de água e de esgotamento sanitário passou a ser visto como assunto também referente ao meio ambiente, inclusive no Brasil (Ribeiro 
\& Rooke, 2010).

O sistema de saneamento básico ainda é visto, em praticamente todos os países, como um serviço de grande importância para o interesse público do qual seu fornecimento à população deve ser de incumbência do poder público. Do mesmo modo, são vistos como atividades locais intimamente ligadas ao planejamento, à organização e à gestão das cidades, em particular nas áreas urbanas, e também em vilas e povoados rurais (Peixoto, 2013).

Peixoto (2013) também indica que o cenário atual ainda representa um panorama confuso da gestão dos serviços de saneamento básico, onde cita problemas como:

- Municípios onde ainda não há uma política municipal formalmente instituída ou quaisquer instrumentos normativos ou regulatórios;

- Legislação e regulação municipais insuficientes ou inadequadas para a gestão dos serviços;
- Convênios de cooperação e contratos de programas celebrados entre municípios e estados e as respectivas empresas de saneamento para a prestação dos serviços de abastecimento de água e esgotamento sanitário, sem observar, em essência, os artigos 30, 175 e 241 , da Constituição Federal de 1988, e as Leis no $11.107 / 2005$ e no $11.445 / 2007$.

De acordo com Tereza e Razzolini (2008), temas relativos ao acesso à água potável têm causado sérias preocupações, principalmenteempaísesqueseencontram em desenvolvimento como o Brasil, que acabam por ter uma larga expansão urbana, adensamento populacional e a ocupação de áreas periféricas e rurais, com evidentes deficiências e dificuldades para o fornecimento de água para satisfazer às necessidades básicas diárias.

O abastecimento adequado de água, em quantidade e qualidade, é primordial para o desenvolvimento socioeconômico da localidade, com impactos diretos sobre as condições de saúde e de bem-estar da população.

Quadro 2. Doenças relacionadas com o abastecimento de água.

\begin{tabular}{|c|c|c|c|}
\hline $\begin{array}{l}\text { GRUPO DE } \\
\text { DOENÇAS }\end{array}$ & $\begin{array}{l}\text { FORMA DE } \\
\text { TRANSMISSÃO }\end{array}$ & $\begin{array}{c}\text { Principais } \\
\text { DOENÇAS E } \\
\text { AGENTE ETIOLÓGICO }\end{array}$ & FORMAS DE PREVENÇÃO \\
\hline $\begin{array}{c}\text { Doenças } \\
\text { diarreicas e } \\
\text { verminoses }\end{array}$ & $\begin{array}{l}\text { Ingestão de água com } \\
\text { contaminantes, má higiene } \\
\text { dos alimentos e a forma de } \\
\text { tratamento dos dejetos. }\end{array}$ & $\begin{array}{l}\text { Cólera (Vibrio cholerae); } \\
\text { Giardíase (Giardia lamblia); } \\
\text { Criptosporidíase } \\
\text { (Cryptosporidium parvum); } \\
\text { Febre tifoide (Salmonella typhi); } \\
\text { Febre paratifoide (Salmonella paratyphi } \\
\text { dos tipos "A", "B"ou "C"); } \\
\text { Amebíase (Entamoeba hystolitica); } \\
\text { Hepatite infecciosa (vírus: "A" e "B"); } \\
\text { Ascaridíase (Ascaris lumbricoides). }\end{array}$ & $\begin{array}{l}\text { A educação sanitária, o saneamento e a melho- } \\
\text { ria do estado nutricional. } \\
\text { Implantar sistema de abastecimento e trata- } \\
\text { mento da água, com fornecimento em quanti- } \\
\text { dade e qualidade para uso e consumo humano. } \\
\text { Proteção de contaminação dos mananciais e } \\
\text { fontes de água. }\end{array}$ \\
\hline $\begin{array}{l}\text { Doenças da } \\
\text { pele }\end{array}$ & $\begin{array}{l}\text { Relacionadas com os hábi- } \\
\text { tos de higiene. }\end{array}$ & $\begin{array}{l}\text { Impetigo (Staphylococcus aureus); } \\
\text { Dermatofitose e micoses (fungos dos } \\
\text { gêneros Trichophyton, Microsporum e } \\
\text { Epidermophyton); Escabiose (Sarcoptes } \\
\text { scabiei); Piodermite (Sarcoptes scabiei). }\end{array}$ & $\begin{array}{l}\text { Não permitir banhos de banheira, piscina ou } \\
\text { de mar. } \\
\text { Lavar frequentemente as mãos com água e } \\
\text { sabão }\end{array}$ \\
\hline $\begin{array}{l}\text { Doenças dos } \\
\text { olhos }\end{array}$ & $\begin{array}{l}\text { A falta de água e a higiene } \\
\text { pessoal insuficiente criam } \\
\text { condições favoráveis a sua } \\
\text { disseminação. }\end{array}$ & Conjuntivites (vírus e bactérias). & $\begin{array}{l}\text { Evitar aglomerações ou frequentar piscinas de } \\
\text { academias ou clubes e praias. }\end{array}$ \\
\hline $\begin{array}{l}\text { Transmitidas } \\
\text { por vetores }\end{array}$ & $\begin{array}{l}\text { As doenças são propagadas } \\
\text { por insetos cujos ciclos pos- } \\
\text { suem uma fase aquática. }\end{array}$ & $\begin{array}{l}\text { Malária (Plasmdium vivax, P. falciparum, } \\
\text { P. malariae); } \\
\text { Dengue (DENV } 1,2,3 \text { e } 4) \text {; } \\
\text { Febre amarela (vírus do gênero Flavivi- } \\
\text { rus); } \\
\text { Filariose (Wuchereria bancrofti). }\end{array}$ & $\begin{array}{l}\text { Eliminar os criadouros de vetores com inspe- } \\
\text { ção sistemática e medidas de controle (drena- } \\
\text { gem, aterro, etc). } \\
\text { Dar destinação final adequada aos resíduos } \\
\text { sólidos. }\end{array}$ \\
\hline $\begin{array}{l}\text { Associada à } \\
\text { água }\end{array}$ & $\begin{array}{l}\mathrm{O} \text { agente etiológico penetra } \\
\text { pela pele ou é ingerido. }\end{array}$ & $\begin{array}{l}\text { Esquistossomose (Schistosoma mansoni); } \\
\text { Leptospirose (Bactéria do gênero Leptos- } \\
\text { pira). }\end{array}$ & $\begin{array}{l}\text { Evitar o contato com águas infectadas. } \\
\text { Proteger mananciais. } \\
\text { Adotar medidas adequadas para disposição do } \\
\text { esgoto. } \\
\text { Combate do hospedeiro intermediário. } \\
\text { Cuidados com a água para consumo humano. } \\
\text { Cuidados com a higiene, destino, adequados } \\
\text { de dejetos. }\end{array}$ \\
\hline
\end{tabular}


Um adequado abastecimento resulta em melhoria na qualidade de vida e em outros benefícios como controle e prevenção de doenças, prática de hábitos higiênicos conforto e bem-estar, aumento da expectativa de vida e da produtividade econômica.

Quando se trata de recursos hídricos devem-se considerar os riscos associados ao consumo de água. Tais riscos podem ser imediatos ou em médio e longo prazo. Durante o ciclo da água, as contaminações podem ocorrer de forma isolada ou generalizada, reduzindo a qualidade da água e o seu uso pode estar parcialmente ou totalmente inadequado (FUNASA, 2015).

De acordo com a FUNASA (2015), as doenças de origem biológica relacionadas com a água podem estar associadas ao uso inadequado da água ou déficit da mesma. O Quadro 2 apresenta os cinco grupos de doenças associadas à água, forma de transmissão e prevenção.

Do mesmo modo, FUNASA (2015) relata que o esgoto deve ser controlado pelo saneamento para evitar, ou reduzir, os impactos negativos sobre a saúde, o ambiente e o desenvolvimento econômico e social de uma população devido ao seu alto teor de contaminação fecal que atinge também os recursos hídricos, e assim sendo responsável por um grande número de doenças. O Quadro 3 apresenta tais moléstias e suas principais e medidas de prevenção.

De acordo com FUNASA (2015), as definições de saúde, saneamento e meio ambiente estão intimamente ligadas. $\mathrm{O}$ destino correto dos esgotos é de suma importância para a saúde pública, pretendendo o controle e a prevenção de doenças associadas. Desta forma, estariam sendo evitadas a poluição do solo e a degradação dos recursos hídricos para o abastecimento e o contato de vetores com as fezes, além de melhorar as condições sanitárias do local e reduzir os gastos públicos com campanhas de imunização e/ou erradicação de doenças endêmicas ou epidêmicas. Portanto, o saneamento básico é fundamental para a qualidade de vida.

\section{Considerações Finais}

Sistemas de abastecimento de água e de esgotamento sanitário, pelos benefícios que geram nas populações, precisam ser eficientes e universais. Para isso, são necessários esforços em dois segmentos. O primeiro diz respeito à importância de abordagens tecnológicas apropriadas na concepção, projeto, implementação, operação e manutenção das unidades e sistemas. O segundo é o fato do saneamento encontrar-

Quadro 3. Doenças relacionadas por contaminação de fezes e medidas de prevenção.

\begin{tabular}{|c|c|c|c|}
\hline DOENÇAS & Agente Patogênico & Transmissão & MEDIDA \\
\hline $\begin{array}{c}\text { Bactéria } \\
\text { Febre tifoide e } \\
\text { paratifoide } \\
\text { Cólera } \\
\text { Diarreia aguda }\end{array}$ & $\begin{array}{l}\text { Salmonella typhi e para- } \\
\text { typhi } \\
\text { Vibrio cholerae } \mathrm{O} 1 \text { e } \mathrm{O} 139 \\
\text { Shigella sp. } \\
\text { Escherichia coli, } \\
\text { Campylobacter } \\
\text { Yersinia enterocolitica }\end{array}$ & Fecal-oral em relação à água. & $\begin{array}{l}\text { Abastecimento de água (implantação e/ou am- } \\
\text { pliação de sistema). }\end{array}$ \\
\hline $\begin{array}{c}\text { Vírus } \\
\text { Hepatite A e E } \\
\text { Poliomielite } \\
\text { Diarreia aguda }\end{array}$ & $\begin{array}{l}\text { Virus da hepatite A } \\
\text { Virus da poliomielite } \\
\text { Virus Norwalk } \\
\text { Rotavirus } \\
\text { Astrovirus } \\
\text { Adenovirus } \\
\text { Calicivirus }\end{array}$ & Fecal-oral em relação à água. & Imunização Qualidade da água/desinfecção. \\
\hline $\begin{array}{l}\text { Protozoário } \\
\text { Diarreia aguda } \\
\text { Toxoplasmose }\end{array}$ & $\begin{array}{l}\text { Entamoeba histolytica } \\
\text { Giardia lamblia } \\
\text { Cryptosporidium spp. } \\
\text { Balantidium coli } \\
\text { Toxoplasma gondi }\end{array}$ & Fecal-oral em relação à água. & $\begin{array}{l}\text { Instalações sanitárias (implantação e manu- } \\
\text { tenção). }\end{array}$ \\
\hline $\begin{array}{c}\text { Helmintos } \\
\text { Ascaridíase } \\
\text { Tricuríase } \\
\text { Ancilostomíase } \\
\text { Esquistosso- } \\
\text { mose } \\
\text { Teníase } \\
\text { Cisticercose }\end{array}$ & $\begin{array}{l}\text { Ascaris lumbricoides } \\
\text { Trichuristrichiura } \\
\text { Ancylostoma duodenale } \\
\text { Schistosoma mansoni } \\
\text { Taenia solium } \\
\text { Taenia saginata } \\
\text { Taenia solium }\end{array}$ & $\begin{array}{l}\text { Fecal-oral em relação ao solo (geohel- } \\
\text { mintose); } \\
\text { Contato da pele com água contaminada; } \\
\text { Fecal-oral em relação à água e alimentos } \\
\text { contaminados; } \\
\text { Ingestão de carne mal cozida. }\end{array}$ & $\begin{array}{l}\text { Esgotamentos sanitários (implantação e/ou } \\
\text { ampliação de sistema); } \\
\text { Higiene dos Alimentos. }\end{array}$ \\
\hline
\end{tabular}


se intrínseco às políticas públicas, onde se necessita auxílio do poder público para a formulação, avaliação, organização das legislações e demais programas voltados para o tema.

Por esta ótica entende-se que existem legislações nacionais, estaduais e em diversos municípios que tratam da temática, mas ainda é necessário maior efetividade no seu cumprimento, a fim de garantir não somente água potável e esgotamento sanitário, mas uma vida de qualidade à população.

\section{Referências}

BRASIL. Constituição (1988). Constituição da República Federativa do Brasil. Brasília, 1988. Disponível em: < http://www.planalto.gov.br/ccivil_03/ constituicao/ constituicao.htm> Acesso em: 05 de maio de 2018.

BRASIL, Lei n. 11.445, de 5 de janeiro de 2007.Estabelece diretrizes nacionais para o saneamento básico. Diário Oficial da União, Brasília, DF 08 jan. 2007. Disponível em: < http://www.planalto.gov.br/ccivil_03/_ato20072010/2007/ lei/111445 .htm> Acesso em: 10 de abril de 2018.

BRASIL, Lei n. 9.433, de 8 de janeiro de 1997. Institui a Política Nacional de Recursos Hídricos, cria o Sistema Nacional de Gerenciamento de Recursos Hídricos. Diário Oficial da União, Brasília, DF 08 jan. 2007. Disponível em: < http://www.planalto.gov.br/ccivil_03/1 eis/19433.htm> Acesso em: 10 de abril de 2018 .

BRASIL, Lei n. 10.257, de 10 de julho de 2001. Estabelece diretrizes gerais da política urbana. Diário Oficial da União, Brasília, DF 10 jul. 2001. Disponível em: < http://www.planalto.gov.br/ccivil_03/leis/leis_2001/110257.htm> Acesso em: 10 de abril de 2018.

BRASIL, Decreto n. 5.440, de 4 de maio de 2005. Estabelece definições e procedimentos sobre o controle de qualidade da água de sistemas de abastecimento e institui mecanismos e instrumentos para divulgação de informação ao consumidor sobre a qualidade da água para consumo humano. Diário Oficial da União, Brasília, DF 4 mai 2005. Disponível em: < http:// www.planalto.gov.br/ccivil 03/ ato2004-2006/2005/decreto/d5440.htm> Acesso em: 12 de abril de $20 \overline{1} 8$.

BRASIL. MINISTÉRIO DA SAÚDE. Portaria n. 2.914, de 12 de dezembro de 2011. Dispõe sobre os procedimentos de controle e de vigilância da qualidade da água para consumo humano e seu padrão de potabilidade. Diário Oficial da União, Brasília, DF 12 dez 2011. Disponível em: < http://bvsms.saude. gov.br/bvs/saudelegis /gm/2011/prt2914 12 12 2011.html> Acesso em: 05 de abril de 2018 .

BRASIL. MINISTÉRIO DO MEIO AMBIENTE. Resolução CONAMA n. 357, de 17 de março de 2005. Dispõe sobre a classificação dos corpos de água e diretrizes ambientais para o seu enquadramento, bem como estabelece as condições e padrões de lançamento de efluentes. Diário Oficial da União, Brasília, DF 17 de mar 2005. Disponível em: < http://www.mma.gov.br/port/ conama/legiabre.cfm?codlegi $=459>$ Acesso em: 05 de abril de 2018 .

BRASIL. MINISTÉRIO DO MEIO AMBIENTE. Resolução CONAMA n. 397, de 3 de abril de 2008. Dispõe sobre a classificação dos corpos de água e diretrizes ambientais para o seu enquadramento, bem como estabelece as condições e padrões de lançamento de efluentes. Diário Oficial da União, Brasília, DF 03 abr 2008. Disponível em: < http://www.mma.gov.br/port/ conama/legiabre.cfm?codle gi=563> Acesso em: 05 de abril de 2018 .

BRASIL. MINISTÉRIO DO MEIO AMBIENTE. Resolução CONAMA n. 377, de 9 de outubro de 2006. Dispõe sobre licenciamento ambiental simplificado de Sistemas de Esgotamento Sanitário. Diário Oficial da União, Brasília, DF 09 out 2006. Disponível em: < http://www.mma.gov.br/port/ conama/legiabre.cfm?codlegi=507> Acesso em: 05 de abril de 2018.

BRASIL. MINISTÉRIO DO MEIO AMBIENTE. Resolução CONAMA n. 396, de 3 de abril de 2008. Dispõe sobre a classificação e diretrizes ambientais para o enquadramento das águas subterrâneas e dá outras providências. Diário Oficial da União, Brasília, DF 03 abr 2008. Disponível em: < http://www. mma.gov.br/port/ conama/legiabre.cfm?codlegi=562> Acesso em: 05 de abril de 2018 .
BRASIL. MINISTÉRIO DO MEIO AMBIENTE. Resolução n. 430, de 13 de maio de 2011. Dispõe sobre as condições e padrões de lançamento de efluentes, complementa e altera a Resolução no 357, de 17 de março de 2005. Diário Oficial da União, Brasília, DF 13 mai 2011. Disponível em: $<$ http://www.mma.gov.br/port/conama/legiabre.cfm?codlegi=646> Acesso em: 05 de maio de 2018

FUNASA. Manual de Saneamento. Brasília: Ministério da Saúde, 4 ed, 2015. Disponível em: < https://funasamy.sharepoint.com/personal/imprensa funasa_gov_br/Documents/Biblioteca_Eletronica/Engenharia_de_Saude Publica/eng saneam2.pdf?slrid=e36e859e-7034-6000-3029-4f4e1d7e45ac $>$ Acesso em: 13 de abril de 2018.

GAZOLA, L. Avaliação da Água de Abastecimento e a Prevalência das Patologias de Veiculação Hídrica em uma Comunidade do Morro do Quilombo - Florianópolis/Sc. [s.1.] Universidade Federal de Santa Catarina, 2008. Disponível em: <https://core.ac.uk/download/pdf/30401478.pdf>. Acesso em: 05 de junho de 2018 .

GIAFFERIS, G. P. Saneamento básico e saúde pública. São Carlos Universidade de São Paulo, p. 1-66, 2001. Disponível em: < https:/ docplayer.com.br/4662809-Saneamento-basico-e-saude-publica.html>. Acesso em: 24 de junho de 2018

HELLER, L. Relação entre saúde e saneamento na perspectiva do desenvolvimento. Ciência \& Saúde Coletiva, v. 3, n. 2, p. 73-84, 1998. Disponível em: <http://www.scielo.br/pdf/csc/v3n2/7152.pdf > . Acesso em: 02 de abril de 2018

LEONETI, A. B; PRADO, E. L. DO\& OLIVEIRA, S. V. W. B. DE. Saneamento básico no Brasil: considerações sobre investimentos e sustentabilidade para o século XXI *. Revista de Administração Pública, São Paulo, v. 45, n. 2, p. 331-348, nov.2010. Disponível em: < http://www. scielo.br/pdf/rap/v45n2/03.pdf $>$. Acesso em: 02 de abril de 2018.

PEIXOTO, J. B. Saneamento básico: política, marco legal e instrumentos de gestão dos serviços. Fundação Vale, 2013.

RIBEIRO, J. W. \&ROOKE, J. M. S. Saneamento Básico e sua Relação com o Meio Ambiente e a Saúde Pública. Juíz de Fora - MG: Universidade Federa de Juiz de Fora, 2010. Disponível em: < http://www.ufjf.br/analiseambiental/ files/2009/11/TCC-SaneamentoeSa\%C3\%BAde.pdf>. Acesso em 24 de junho de 2018

SISTEMA NACIONAL DE INFORMAÇÕES SOBRE SANEMENTO Diagnóstico dos Serviços de Água e Esgotos. 2016. Disponível em: < http:// etes-sustentaveis.org/wp-content/uploads/2018/03/Diagnostico_AE2016. pdf $>$. Acesso em: 05 jun. 2018.

SPERLING, M. V., et al. Manual de Saneamento e Proteção Ambiental para os Municípios. vol. 2, 4. ed. Belo Horizonte: Editora UFMG, 2003.

TEREZA, M.\& RAZZOLINI, P. Impactos na saúde das deficiências de acesso a água Impactos na Saúde das Deficiências de Acesso a Água. Biblioteca Digital da Produção Intelectual - BDPI da Universidade de São Paulo, São Paulo, v. 17, n1, p. 21-32, 2008. Disponível em: <http://www.revistas.usp. br/sausoc/article/view/ 7557/9077> . Acesso em: 05 de abril de 2018.

TSUTIYA, M. T. Abastecimento de Água. 3. ed. São Paulo: Departamento de Engenharia Hidráulica e Sanitária da Escola Politécnica da Universidade de São Paulo, 2006.

UNGLERT, C. V. S., 1995. Territorialização em sistemas de saúde. In Distrito Sanitário (E. V. Mendes, org.), pp. 221-235, São Paulo: Editora Hucitec/Rio de Janeiro: ABRASCO.

VIEITES, E. G. Atlas de saneamento 2011 - Acesso e qualidade das redes de saneamento segundo as Unidades da Federação. Instituto Brasileiro de Geografia e Estatística - IBGE: Rio de Janeiro, 2008. Disponível em: $<$ https://biblioteca.ibge.gov.br/visualizacao/livros/liv53 096 cap7.pdf $>$. Acesso em: 24 de junho de 2018.

WORLD HEALTH ORGANIZATION. Investing in Water and Sanitation: Increasing Access, Reducing Inequalities. WHO Library Cataloguingin-Publication Data UN-water,[S. 1. : s. n.], 2014. Disponível em: $<$ http:// apps.who.int/iris/bitstream/handle/10665/139735/9789241508087 eng. pdf? sequence $=1>$. Acesso em: 02 de abril de 2018 . 